\title{
Chapter 8: Tensions Between Financial and \\ Organisational Sustainability: The Problematic Case \\ of Group-Based Microfinance and Possible Ways Forward
}

\section{Ana Marr}

\section{Introduction}

A number of chapters in this volume have spoken to possible ethical problems arising from the operation of the group model in microcredit. This chapter takes up a distinct but significantly related set of issues concerning the empirical assumptions made about the group model. That is, there is something fundamentally limiting in most of the theoretical models that try to understand the workings of group-based microfinance. They correctly identify the fact that a lack of information and high transaction costs help explain the limited access of the poor to finance. They also tend, however, to presume that because group members are jointly or collectively responsible for loans, they have sufficient incentive to raise and share information about their peers in order to secure prompt repayment of loans, leading to financial sustainability. In other words, they presume that group members have almost perfect information about their fellow members, and that they can monitor their actions and enforce repayment without costs (see Marr 2003).

This chapter, which draws on findings from a 3-year research project, adds to the large body of literature on empirical impact studies of microfinance (see Chowdhury and Mosley 2004, Copestake 2007, Duvendack et al 2011), but it assesses impacts from a new angle: the dynamics of group operations. By placing group dynamics at the centre of the investigation, it helps explain the complex response of group members to the reality of being made collectively responsible for each other's loans. In doing so, the study looks at how the institutional aim of attaining financial sustainability strongly influences the sustainability of groups as organisations (and vice versa), with some rather remarkable effects on how 
information is raised and shared within groups, how repayment of loans is made or fails to be made, and how poverty is reduced or aggravated.

Six sections follow this introduction. Section one presents the conceptual framework and methods for the study of microfinance impacts, while sections two to four elaborate key research findings on specific aspects of group dynamics, i.e. group formation, peer monitoring and auditing, and the enforcement of sanctions. Section five contains tentative recommendations to help overcome the failings of group microfinance today, and section six offers some concluding observations.

\section{Conceptual framework, methods and the institution studied}

This section presents an alternative analytical framework for the study of poverty impacts of group-based microfinance schemes (for full details see Marr 2002). The central idea in this framework is that, in order to capture the full costs and benefits of microfinance, the analysis ought to focus on the essence of what constitutes joint-liability microfinance schemes, and hence make the study of group dynamics central to the investigation concerning the power of microfinance in resolving informational problems and alleviating poverty.

In examining group dynamics, two main aspects merit close analysis: the group's financial sustainability and its organisational sustainability. Figure 1 shows possible outcomes resulting from group interactions. One possible outcome is that groups attain both financial and organisational sustainability, with growing and stable loans and savings levels and stronger ties among members. Other outcomes reflect the potential trade-off between those two objectives, while a final outcome could be the total collapse of groups. 
Figure 1. Possible Outcomes of Group Dynamics

\begin{tabular}{|c|c|c|c|}
\hline \multicolumn{4}{|c|}{ Financial sustainability } \\
\hline \multirow{3}{*}{$\begin{array}{l}\text { Organisational } \\
\text { sustainability }\end{array}$} & & $(+)$ & $(-)$ \\
\hline & $(+)$ & $\begin{array}{l}\text { Increasing loan and } \\
\text { savings growth rates } \\
\text { Growing or stable } \\
\text { membership rates } \\
\text { High repayment rates } \\
\text { Stronger ties in the group }\end{array}$ & $\begin{array}{l}\text { Decreasing loan and } \\
\text { savings growth rates } \\
\text { Mismanagement of } \\
\text { internal loan accounts } \\
\text { Uneven repayment rates } \\
\text { Stronger ties in the group }\end{array}$ \\
\hline & $(-)$ & $\begin{array}{l}\text { Fragmentation of the } \\
\text { group as a network } \\
\text { High membership } \\
\text { turnover } \\
\text { Individualistic behaviour } \\
\text { Lower social interaction } \\
\text { Exclusion of the poorest } \\
\text { High repayment rates }\end{array}$ & Group break-up \\
\hline
\end{tabular}

The conceptual framework also identifies five stages in the development of microfinance groups. A formation period is when the selection of potential group members takes place. Once formed, groups gradually evolve over the three years of their intended life and go through three typical stages of development: a learning period, during which people gain knowledge about rules and members' personal traits; a critical period, in which unresolved problems and potential conflicts usually lead to significant changes in intra-group interactions; and a consolidation period, during which new resolutions can result in the success or failure of the microfinance group. The length and presence of each of these periods are obviously not clear-cut, as groups may jump one particular period or never reach the next expected developmental stage.

The validity of this framework was tested empirically during field research in the rural communities of Cusco in southern Peru, and semi-urban shantytowns of the capital, Lima, during 2000-2001. Nine groups were randomly selected from a Communal Banking programme called La Chanchita. This microfinance programme works with groups of around 20 people each; groups have an operative life of three years, after which time they 
disintegrate or begin another phase of three years; and it targets poor and disadvantaged segments of the population. The total sample of group members was around 280, including founders of groups, members who exited the programme before its end, and new members who entered existing groups. In addition, a total of approximately 200 people were interviewed, including control group participants, microfinance officers and senior managers, some household members, and key informants in the local communities. Methods for collecting information included quantitative and qualitative tools such as surveys, in-depth interviews, focus groups and participatory observation, to ensure a comprehensive understanding of the internal dynamics of groups and to crosscheck information. Results and analysis were compared and contrasted with analyses of other similar organisations in Asia, Africa and Latin America.

\section{Why is it so difficult to form groups?}

During our research into the formation of groups, we looked at how individuals selected group peers and we then classified their responses based on five key aspects of group members' lives: (1) business management, (2) household management, (3) timely repayment of old debts, (4) willingness to honour debts, and (5) exposure to risks. These indicators were identified as relevant for assessing future behaviour and responses during group interactions. The main results were the following:

- Groups were heterogeneous in terms of their members' level of information about the five key indicators. This implies that information about colleagues' defaults risks is imperfect, which has important consequences for levels of loan repayment, group dynamics and poverty more generally.

- Within each larger group of around 20 members, several sub-groups were found. In sub-groups composed of family members, for example, high levels of information were present, while in sub-groups of neighbours who live very far from one another, low levels of information prevailed. 
- Initial information levels are generally superficial across participants. Only around one-fifth of group members have a relatively high degree of knowledge about colleagues, i.e., none claimed perfect information about group members, though this is assumed by some theorists of group-lending schemes.

- Initial knowledge is particularly low with regard to aspects of members' household management (i.e., usage of household income flows and assets, expenditure patterns, and extent of conflictive relationships within household members), and exposure to risks (i.e., members' vulnerability to risks such as those resulting from high numbers of dependent household members, illnesses in the family, and unsafe workplace and household environment). These limitations in knowledge prove to be important constraints to the efficient working of groups.

Various reasons associated with institutional deficiencies, local market changes and actual screening processes were found to explain these outcomes.

\section{Institutional deficiencies}

- The realities of setting 'institutional financial sustainability' as a principal objective in this microfinance organisation mean that officers tend to allocate little time to the process of forming groups.

- Pressures on officers' time for achieving high loan portfolios appear to produce strong incentives for officers to form groups very quickly, in order to start disbursing loans as soon as possible and hence attain their personal performance targets.

- As present performance criteria take into account financial indicators only, officers place little importance on information levels amongst group members, degree of group cohesion, types of prior mutual relationships and actual poverty levels, leading to cases of highly fragmented groups being formed.

\section{Changes in local market}

- The increasing supply of microfinance services in the country was seen as contributing to the difficulties in attracting potential participants to schemes. This was particularly noticeable in the semi-urban areas investigated.

- During 1994 to 2000, the number of microfinance organisations in Peru almost doubled, from 19 to 37, many of which were major competitors of the microfinance programme under study (SBS 2000). The implication of this is that, in many instances, officers do not have any other option but to help form groups composed of people who live in highly dispersed geographical areas and who possess very little knowledge about one another. This is because there is the intention to reach people with no prior involvement with any other microfinance organisation. 


\section{Screening process}

- One important factor in the formation of heterogeneous groups relates to the actual screening process when selecting group members. What is critical here is that people's eligibility criteria do not necessarily coincide with those of the microfinance institution (MFI). While MFIs oblige potential participants to self-select members who will be able and willing to repay loans, people have much more diverse criteria.

Four broad areas where the eligibility criteria deviate from that of MFIs were identified when investigating participants' motivations for selecting group members.

- Within sub-groups of close relatives, one prominent factor in self-selection criteria is the use of loans. In these groupings, members are selected for their readiness to hand over their loans to another relative (usually the one who invited them to participate in the programme) when required. For this purpose, it would not necessarily matter to the selecting participant whether her relative fulfils the MFI's criteria, as long as she complies with the unwritten agreement between them. Their loyalties lie firmly within the household and the extended family, sometimes to the detriment of fellow group members' and even MFI's objectives.

- Needs-based groupings. For these participants the main criteria is the individuals' level of poverty and not necessarily their capacity to repay debts in time. One prominent sentiment within this group is the expectation that MFI rules will make allowances for people's economic situation, particularly when the MFI's selfproclaimed objective of reducing poverty is noted. Thus, members' self-selection criteria emphasise compliance with an institutional objective, which, in practice, has been outweighed by the overriding goal of achieving financial sustainability.

- Amongst members who have binding ties related to patron-client relationships, a fundamental criterion for selection relates to their reciprocal outstanding debts in political favours and money. In these cases, the selecting participant is usually in a position of power within the group and can ignore MFI eligibility criteria without difficulty. People are hence invited to become part of the group by this powerful member with no further questions asked about their ability or willingness to repay loans. One common reason for including 'clients' is to use MFI loans to repay prior debts owed by the 'patron.'

- Weakly associated group. A fourth identifiable broad criterion for self-selection is the need to reach the minimum number of people to start a group - usually 20 persons. In some cases, particularly in urban and semi-urban areas, participants find it hard to select 20 potential members to start the group and have to resort to inviting people they hardly know and with whom no previous relationships exist. Although these participants are likely to fulfil basic MFI requirements, their weak links with colleagues further endanger the group's cohesiveness.

The implications of forming heterogeneous groups are that MFIs will have to rely heavily on members' access to information and set incentives to increase participants' willingness to share that information with group colleagues and officers. 'Hidden agendas' become clear as 
events unfold over the life of the group, and participants start negotiating aspects of their own agendas with those of their colleagues within the framework of institutional objectives.

\section{Limits in Monitoring Behaviour and Auditing Results}

In group-based microfinance, members are expected to monitor their peers' behaviour so that loans are used appropriately and repayments can be made on time. Similarly, they are expected to audit loan usage when repayments fall behind schedule. In both situations, key information about members' activities needs to be raised and shared in order for them to make informed decisions about how to proceed with debtors.

Two significant findings were encountered during our study, which greatly influence the sustainability (or lack of sustainability) of groups.

- Group members undertake very low levels of peer monitoring.

- Peer auditing is done frequently but the quality of auditing is poor and is observed to deteriorate over time.

There were various reasons why monitoring was particularly low among these group-based microfinance schemes:

Transaction costs are high: for nearly $60 \%$ of participants, monitoring took between 1 and 7 days of their time, while one person dedicated as much as two weeks to raising information during peer monitoring. Taking as the benchmark the time devoted to compulsory meetings (i.e. 6-9 hours per year), or the maximum length of time that members expected to dedicate to the programme, time-related costs of monitoring are calculated to be between 3 and 60 times higher. In monetary terms, compared to an appropriate benchmark (the MFI interest rate of US\$0.27 per day), daily monitoring costs are as much as 163 times more expensive. These 
are extraordinarily high costs to bear, and hence appear to represent the most important constraint on the task of peer monitoring.

Re-structuring groups for monitoring purposes is ineffective: To encourage peer monitoring, groups are divided into sub-groups of 2-3 members who become mutual loan guarantors. Lack of effectiveness in this case relates to poor enforcement, methods of sub-group selection, and lack of systematic re-structuring across groups. For example, when an untoward event occurs, lines of liability are not always respected (sometimes no-one is responsible and sometimes the whole group is); sub-groups tend to be composed of close relatives with a strong interest in avoiding monitoring and penalties; and, even in other types of sub-groups, liability tends to be avoided because systems are not introduced on an equal basis across groups.

Progressive lending is hampered by market competition: The promise of progressively larger loan amounts to encourage repayers loses effectiveness due to the increasingly large supply of microfinance services in the communities studied. Indeed, as participants perceive that they can gain access to other financial institutions, the promise of larger loan amounts loses its power to encourage higher levels of peer monitoring.

Information is distorted, hidden or simply not volunteered: Most importantly of all factors, the study found that information needed for peer monitoring is distorted, hidden or simply not volunteered in the process of transferring this information to group members and officers. A fundamental reason for this is that participants' interactions when carrying out monitoring are ruled by deep-seated power structures. These power structures originate from the types of relationships that group members sustain with their peers prior to joining microfinance 
schemes, the bases for which are diverse and not necessarily related to issues of borrowing and lending.

Prior Social Relations and Their Influence in Extent of Information Flows: As noted earlier, group self-selection criteria are based on social ties arising from blood connections, patronclient relations, pro-poor community associations, and neighbourhood and business proximity. Interestingly, only $4 \%$ of all participants have prior relationships based on borrowing and lending, i.e. as members of common Rotating Savings \& Credit Associations. This means that the vast majority of participants are unfamiliar with financial issues when they first join the programme. When these group members are confronted with an alien way of relating to one another - in this particular case, monitoring colleagues' loans, investments, returns, risks, and so on - they tend to react very strongly and may resort to acts of intimidation, threats and even physical abuse in order to repress information about their financial affairs. This is eloquently evidenced by a (representative) commentary made by one of the participants:

"I told group members about our neighbours' comings and goings and that I'd seen that they had just bought a big truck with their loans to take their maize to [the market at] Puno. Two weeks later, someone stole my pigs from my little patch of land. I know that it is that family taking revenge on me. They think they can do anything in the group and no-one should say anything."

(Transcription from fieldwork in Huayllabamba, Cusco, 2000-2001)

What this testimony indicates is not so much limitations on raising information stocks: this person had obtained information about this family's use of loans, and she is not complaining about the costs of raising information. The problem seems to be related, rather, to costs involved in the sharing of information. It is, therefore, in the transmission of information to others that people react very strongly to repress information. This means that the information is accessible but is going to be repressed, distorted, hidden or not volunteered because of the 
costs involved in the sharing of information and because the loyalties of people may lie elsewhere - that is, not in support of the interests of the MFI.

The quoted testimony also raises the question of how effective the MFI is in providing the structures and incentives for a harmonious exchange of information. Two related issues can help us explore this question: the legitimacy of loan usage and the types of communication structures set up by these microfinance schemes.

Ambivalence in defining valid loan usage: In practice, officers sometimes inform group members that it is legitimate to use loans for consumption purposes; at other times their strong message is that loans should be used for investment in income-generating activities only. The root of this ambivalence is that MFIs (and officers) are struggling to achieve simultaneously the two somewhat contradictory objectives of financial sustainability and poverty alleviation. That is, loan usage for consumption-smoothing can be justified by poverty-reduction arguments but not necessarily by financial sustainability arguments. An important consequence of this is that officers tend to change the definition of legitimacy in loan usage, particularly when running into problems of loan recovery, making the task of peer monitoring more difficult to accomplish.

Ineffective communication structures: This leads to various coordination and motivation losses. In monthly General Meetings, where group members and officers convene to exchange information, lines of communication are overwhelmingly centralised in the Credits Committee (i.e. the members who compose the group's central committee, plus the guiding MFI officer), discouraging group members from communicating sensitive information gathered through monitoring. Deliberations in meetings are often affected by tensions arising from disparate agendas, and the interests of the centralised power usually prevail, with little 
regard for the stocks of information gathered by colleagues; hence final decisions (on loan disbursements for example) become highly concentrated in a few hands.

Inability to cope with conflict: There are deficiencies in officers' management of information and conflicts. Despite the number of training courses they take, officers do not seem to have the tools - or perhaps more importantly, the MFI does not provide structures and mechanisms - to manage monitoring and auditing information and the conflicts that develop during information exchange. One crucial deficiency arises when officers leave problems and disagreements resulting from audit discussions completely unresolved. This has serious implications for individual and group behaviour because participants perceive a lack of benefit in sharing audit information with their peers, while they have to endure the social costs that revealing information inevitably brings to them, leading to further deterioration in the quality of auditing.

The consequences of poor channels of communication and centralised decision-making are profound:

- The increase in monitors' transaction costs is magnified by the perception that little real importance is attributed to the information.

- Group members perceive no benefit in conducting monitoring, while they have to bear the costs of undertaking it.

Furthermore, as the quality of auditing deteriorates, group members cannot distinguish between debtors' inability and unwillingness to repay, so all non-payers are classified as strategic defaulters, i.e., unwilling to pay their debts back. 


\section{Sanctions that hurt the poor disproportionately: The failings of group microfinance}

With low levels of monitoring and a strong bias towards labelling participants as strategic defaulters, these microfinance schemes rely very heavily on the imposition of sanctions to achieve high repayment rates. Thus, major failures of group-based microfinance are that:

- The poorest and most vulnerable people from any given group are excluded or leave the group prematurely. Table 1 shows that nearly $70 \%$ of the group members who leave the programme before its end are classified as 'very poor' according to participants' own wealth ranking. Moreover, they are most likely to leave in very large numbers at the beginning of the programme or when the group has 2-3 years of maturity. This phenomenon occurs largely because the very poor are more likely to fall behind with their debts and equally more likely to suffer sanctions due to their being less able to negotiate sanctions and loan repayments, knowing little about legal and civil rights, and being more likely to be intimidated by authority.

Table 1: Members who left the programme before its end

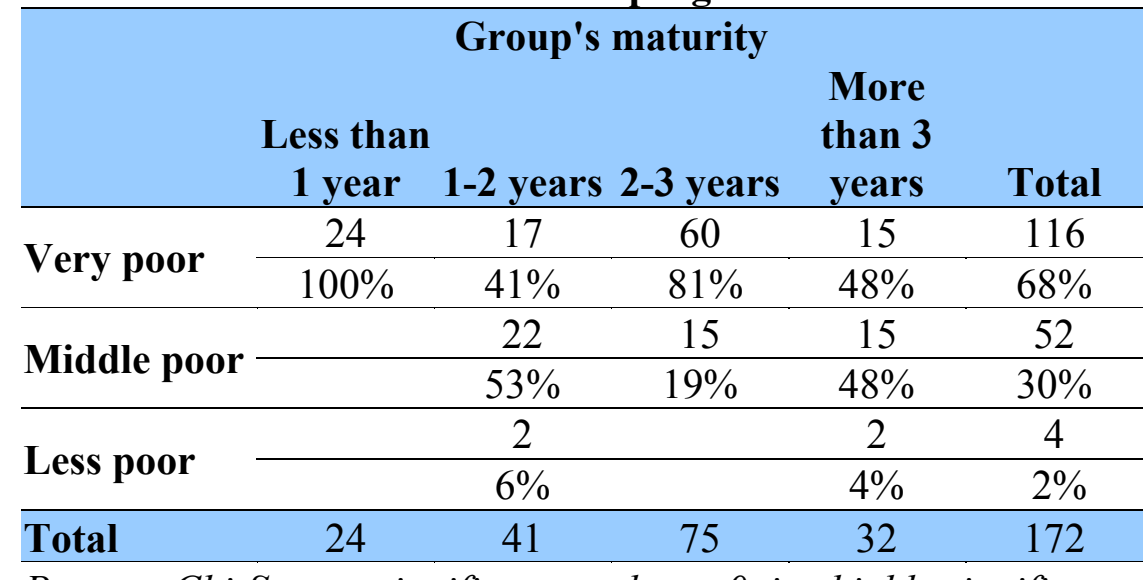

Pearson Chi-Square significance value $=0$, i.e. highly significant

- The joint-liability system appears gradually to be abandoned over time, as the use of social collateral (e.g. group visits) in the administration of sanctions becomes less important than the use of financial and physical collateral. Alarmingly, the practice 
of confiscating participants' assets seems to increase over time: by the end of the programme, an overwhelming $18 \%$ of all sanctions involved confiscation of colleagues' personal assets.

- Furthermore, the impacts on participants who leave are mainly negative. Evidence in table 2 shows that these excluded colleagues go deeper into debt (particularly with moneylenders) in order to repay MFI loans and, if payments are not settled in time, significant personal and household assets are confiscated. These material losses are magnified by losses in terms of broken social relations with group members, which result from often violent confrontations during group interactions. The combined effect is that participants usually end up deeper in poverty than when they started.

Table 2: Forms of loan repayments by exit members

\begin{tabular}{|c|c|c|c|c|}
\hline & \multicolumn{3}{|c|}{ Membership length } & \multirow[b]{2}{*}{ Total } \\
\hline & 1 year & 2 years & 3 years & \\
\hline \multirow{2}{*}{ By instalments } & 3 & 12 & & 15 \\
\hline & $2 \%$ & $23 \%$ & & $9 \%$ \\
\hline \multirow{2}{*}{$\begin{array}{l}\text { Borrowed from } \\
\text { household } \\
\text { members }\end{array}$} & 18 & 5 & 3 & 26 \\
\hline & $17 \%$ & $9 \%$ & $33 \%$ & $15 \%$ \\
\hline \multirow{2}{*}{$\begin{array}{l}\text { Borrowed from } \\
\text { friends }\end{array}$} & 12 & & & 13 \\
\hline & $12 \%$ & & & $8 \%$ \\
\hline \multirow{2}{*}{$\begin{array}{l}\text { Borrowed at } \\
\text { higher interest } \\
\text { rates }\end{array}$} & 30 & 3 & & 33 \\
\hline & $29 \%$ & $5 \%$ & & $19 \%$ \\
\hline \multirow{2}{*}{$\begin{array}{l}\text { Reduced } \\
\text { consumption }\end{array}$} & 3 & 2 & & 5 \\
\hline & $2 \%$ & $5 \%$ & & $3 \%$ \\
\hline \multirow{2}{*}{$\begin{array}{l}\text { Confiscation of } \\
\text { assets / savings }\end{array}$} & 22 & 12 & & 34 \\
\hline & $21 \%$ & $23 \%$ & & $21 \%$ \\
\hline \multirow{2}{*}{ From profits } & 12 & 8 & 5 & 25 \\
\hline & $12 \%$ & $14 \%$ & $67 \%$ & $15 \%$ \\
\hline \multirow{3}{*}{$\begin{array}{l}\text { Have not repaid } \\
\text { yet }\end{array}$} & 5 & 12 & & 17 \\
\hline & $5 \%$ & $23 \%$ & & $10 \%$ \\
\hline & 105 & 55 & 8 & 168 \\
\hline
\end{tabular}

Pearson Chi-Square significance value $=0$, i.e. highly significant 
The post-screening process that results from group dynamics reveals not only that the very poor tend to be induced to leave microfinance programmes, but also that new group members are selected from less poor backgrounds than those of the original participants, leading to a consistent diversion from the target population of the poor towards the better-off. This implies that the process of screening gives rise to the typical inefficiencies of credit markets - whereby the very poor are rationed out of credit schemes.

Two factors above all help to explain all these outcomes:

- The role of collective sanctions; and

- The increasing incentives to default strategically.

The role of collective sanctions: Collective sanctions are of two kinds: (1) when the whole group is denied renewed access to loans; and (2) when group savings are used as loan insurance. The latter type of collective sanction is remarkably important in explaining the findings outlined earlier. Participants are obliged to save 20 per cent of every loan amount that is granted to them. As members are not allowed to withdraw savings before the end of the programme, these accumulate over time and signify an important percentage of present loan amounts: halfway through the membership period, the value of a participant's cumulative savings is equivalent to over 70 per cent of her current loan amount. Collective sanction in this case means that group savings are used by the MFI to repay unpaid debts, which implies that all members are punished as they are made to pay for their colleagues' debts.

This type of collective sanction is in fact the most frequently used sanction because it primarily benefits the vested interests of one particular party: the MFI officers. When group savings cover unpaid debts, the books never go into the red and new loans can be disbursed without delay, leading to attainment of officers' performance targets. Loans are paid on time, repayment rates are high and loan portfolios keep growing. As good group savings 
management is not part of officers' targets, there is no incentive for them to keep group savings in good health. In fact, the majority of groups under study reported serious problems with recovering group savings and a third of them told of default rates of around 60 per cent, figures that are not included in the MFI official repayment rates. ${ }^{1}$

Employing group savings for collective sanctions can dramatically erode group cohesiveness. This is because group savings are supposed to act as collective benefits; that is, the microfinance group is expected to accumulate and manage members' savings in order to make them grow. In other words, these savings are an essential source of group cohesiveness. Profitable investments of group savings include lending these funds to members and nonmembers and setting up collective enterprises and communal activities, all of which leads to greater social cohesion and financial strengthening. When these hard-earned group savings are used as loan insurance and never recovered - because the MFI leaves participants to recover these savings themselves - a deep distrust grows between members and officers, leading to the deterioration of group cohesiveness and the crumbling of the joint-liability system.

Increasing incentives to default strategically: Evidence shows that using group savings as a collective sanction encourages participants to default strategically, particularly those members who always repay their loans on time. This is because when group savings face imminent loss, participants feel that they are being penalised for good behaviour and begin devising strategies to default on loans in order to make use of their individual savings: Some decide to default immediately and let MFIs withdraw their individual savings to repay these debts. By deciding to default strategically rather than repaying loans and risking losing their individual savings if group savings are never recovered, they make sure that their own

\footnotetext{
${ }^{1}$ These report repayment rates of MFI loans only, which, given the practice of loan insurance, are consequently very high, distorting the real financial position of most microfinance groups.
} 
savings are of some benefit to them. Others decide to exit the group for one cycle and re-enter later. In this way, they can withdraw their individual savings, avoiding a total loss if group funds are not recovered. As potential default risks surge, members become more distrustful of colleagues' future behaviour, cooperative instincts vanish and the cohesiveness of groups rapidly disintegrates. In some cases, default risks increase to such high levels that the whole group collapses and, with no savings and broken relations, most participants end up worse off.

Throughout this process, the costs and risks suffered by members prompt them to react very strongly against sanctions, refusing to allow group savings to be used as loan insurance. In parallel with this tendency to abandon social collateral, an introduction of individuallybased collateral (such as financial and physical collateral) demonstrates a clear intention on the part of group members to transfer back to the MFI those costs and default risks that microfinance hoped to eliminate when working with joint-liability systems.

\section{Recommendations to help improve group microfinance}

In this section, we suggest some of the most important institutional changes necessary to help improve group microfinance.

Re-balancing the institutional objectives: There is an urgent need to re-balance the broad institutional goals of microfinance - financial sustainability and organisational sustainability - in order to make the system a valuable contribution towards the reduction of poverty. It has been shown in this chapter that an overemphasis on attaining financial sustainability undermines cooperation and accentuates unequal power relations to the detriment of vulnerable people and group cohesion. It could be argued, then, that by putting more or most 
weight on the goal of 'organisational sustainability,' social relations and well being could be improved, and therefore group finances would have a better chance of becoming sustainable.

In this alternative, more balanced approach, the treatment 'groups' do not only promote the goal of financial sustainability. Rather they are recognized as ends in themselves: the importance of groups is explicitly acknowledged in assisting the poor to overcome obstacles collectively and helping improve the livelihoods of their members and of communities at large.

Having a re-balanced mission is not enough, however. For this to be a workable strategy, it is necessary to build appropriate systems including those of information and communication exchange as well as effective incentive structures.

Information and communication systems: Information and communication systems are important at three levels of interaction: between the microfinance institution and its credit officers, between officers and clients; and between clients, i.e. microfinance group members.

- MFI-officers: Appropriate systems for ensuring sound information exchange and enhancing communication between the organisation and officers include:

- Clear job descriptions, taking into account the differential duties for officers working in, for example, rural and remote areas and with poorer clients.

- Regular meetings for discussions about work duties and possible changes in job descriptions as needs arise.

- Clear and transparent staff performance indicators and the rewards and sanctions attached to them.

$\circ$ Flexibility and easy access to managers when officers have concerns and need to discuss issues prior to the regular group meetings.

- Officers-clients: The study's findings show significant negative effects that ultimately originate from deficient information and communication systems between officers and beneficiaries. These could be minimised through: 
- Giving clients full information about potential benefits and costs of participation in microfinance programmes - avoiding false accounts of possible costs.

- Clear eligibility criteria - to provide clear parameters within which self-selection of group members can take place. If criteria change over time, this should be conveyed to clients, giving the reasons why and indicating when new criteria apply (see also Balkenhol 2007).

- Clear definition of valid loan usage, if applicable. When loan usage is flexible, this should be explained clearly at the start of group operation, highlighting the limits of what is acceptable and what is not.

- Regular meetings should have a clear agenda and allow enough time for proper discussion of issues.

○ Democratic decision-making: Major decisions affecting groups, e.g. election of new central committee, should be discussed openly in meetings and majority voting should be requested for a final decision to be reached.

- Conflict management: Officers should be trained in conflict management to be able to deal with issues arising in meetings.

- Accountability of decisions: Roles of officers, central committees and other group members need to be clearly defined in order to set the degree of accountability of each in decision-making and action taking.

- Transparency: Minutes of meetings should provide evidence of issues for discussion and decisions taken. The officer and a designated group member (acting as secretary) must keep records of minutes and share them with all group members.

- Management Information Systems: Simple MIS software ought to incorporate records of important decisions and actions taken between officers and groups. These records could then be used by superiors when appropriate (see also Hermes et al 2011).

- Among group members: In order to help enhance information and communication flows amongst group members, MFIs should:

- Promote ownership: The sub-rules governing groups must be defined by groups themselves. However, the parameters set up by institutions ought to be clearly stated and conveyed to groups by officers (see also Mersland and Strom 2008).

- Institute democratic systems: Particularly in the governing structure of groups, it is indispensable to set up fair voting systems, which would allow the formation of central committees. Regular rotation of committees should be encouraged.

$\circ$ Empower the voiceless and poorest members: Through transparent and democratic forums for discussion where all members would have the opportunity 
to be heard and their concerns to be taken into account (see also Kabeer 2005).

- Form systematic monitoring groups: In large groups, there might be a need for sub-groups due to peer monitoring reasons. Criteria for forming sub-groups should be clearly defined and explained to groups - this will determine the performance and level of monitoring.

- Encourage exchange of truthful information: By clearly explaining to groups the reasons why information needs to be raised and shared with members, and the consequences of it. Rewards and sanctions need clear definition and should be applied only after solid evidence has been provided.

\section{Incentive structures:}

Incentive structures for assessing staff performance are defective in group microfinance schemes. Staff incentives have tended to be based on highly visible indicators such as repayment rates and number of clients. Social indicators such as poverty levels and group cohesiveness have in general been ignored. To help re-balance performance indicators MFIs should:

- Re-engineer performance management systems so that officers' interests and rewards are tied to group cohesiveness and poverty alleviation. Staff appraisal, rewards and penalties need to be linked to indicators that reflect social institutional commitments as well as the financial aims of microfinance (see also Rai and Sjöström 2004).

- Use performance indicators aimed at maintaining a healthy group organisational development. Some of these may be subtle and not as visible as financial indicators. They include: number and type of elections, number and poverty level of drop-outs, type of clients' misconduct and the corresponding sanction, number and nature of group meetings, amount and stability of group savings, and repayment rates of loans from group savings accounts.

- Adopt performance indicators that enhance impacts on poverty alleviation. Here, three broad areas need highlighting: depth of outreach in poorer populations, breadth of outreach, and impacts on livelihoods. A simple and clear set of indicators should be derived in order to serve as a pointer for assessment of officers' performance. This should reflect the institution's poverty aims and ability to deliver. ${ }^{2}$

- Avoid purely individual incentive structures in favour of collective incentives: Competition amongst staff is desirable up to a point, but it is also likely to lead to weak teamwork and institutional inefficiencies. To help promote co-operative effort, incentive structures ought to be set up at two other levels: (1) At the branch level,

\footnotetext{
${ }^{2}$ See also Copestake 2007 for new ways to manage the social performance of microfinance.
} 
where annual surplus can be shared with staff based on an aggregate score of a core of performance indicators; and (2) At the institutional level, where annual profits are shared with branches and staff depending on degree of achievement and good performance (see also Marr et al 2014).

\section{Safeguards for protection of group savings:}

- The study has shown that group savings are vulnerable to mismanagement and potential loss. How can these effects be minimized? In the absence of formal banks in the locality, group savings are best kept in the microfinance organisation office to ensure safety of deposits and prudent management. Acceptable record keeping by the group's central committee and their ability to instil within clients the importance of savings could also be enhanced through tailor-made training on these aspects of finance. Alternatively, group savings can be kept in the form of seed or livestock by the group itself.

- To reduce risks of collective loan default (and hence the likelihood of using group savings as loan-insurance), groups should have a mix of income-generating activities. If the cash-flow cycles of these activities are varied, there is a higher likelihood that some members will be able to repay loans when others have difficulties. Equally, it is more likely that widespread shocks, such as crop diseases, will not lead to collective default if some members are involved in non-farm activities.

- Monitoring and evaluation systems are essential for the development of group savings. Over time, a model appropriate to the conditions in a particular area will probably emerge. Recovery of group savings, when used to cover for late loan repayment, is essential in maintaining trust in the institution. Greater involvement of officers and credible systems to recover savings include, for example, the use of incentives for drop-outs to return to the institution and facilities to repay their (unpaid) loans, leading to the recovery of group savings.

\section{Conclusion}

The chapter has highlighted some aspects of group microfinance, which result in the exclusion (or self-exclusion) of some of the poorest and most vulnerable members, with serious negative impacts on their well-being. The chapter also reveals a move away from targeting poor segments of the population to less poor sectors, meaning that poorer people are rationed out of microfinance markets.

Two main lessons can be derived from the preceding analysis: (1) to avoid poor outcomes, microfinance institutions have to look at the internal dynamics of groups and the types of behavioural strategies that are being encouraged in group members and officers. (2) to help enhance impacts, it is crucial to tackle the issue of organisational sustainability. Introducing more appropriate information and communication systems as well as effective incentive structures, such as those suggested in the chapter, could therefore assist microfinance institutions in achieving financial sustainability and poverty reduction at the same time. 


\section{Works Cited}

Balkenhol, B (ed) (2007) Microfinance and Public Policy: Outreach, Performance and Efficiency. Palgrave Macmillan

Copestake J (2007) Mainstreaming Microfinance: Social Performance Management or Mission Drift? World Development 35 (10): 1721-1738.

Chowdhury, M and P Mosley (2004), eds, The Social Impact of Microfinance. Special Issue. Journal of International Development, vol. 16, no.3.

Duvendack, M, R Palmer-Jones, J Copestake, L Hooper, Y Loke and N Rao (2011) What is the evidence of the impact of microfinance on the well-being of poor people? London: EPPI-Centre, Social Science Research Unit, Institute of Education, University of London.

Hermes N, R Lensink and A Meester (2011) Outreach and Efficiency of Microfinance Institutions. World Development 39 (6): 938-948.

Kabeer N (2005) Is microfinance the 'magic bullet' for women's empowerment: analysis of findings from South Asia. Economic and Political Weekly 29/20/2005: 4709-4718.

Marr, A (2002) Studying Group Dynamics: An Alternative Analytical Framework for the Study of Microfinance Impacts on Poverty Reduction. Journal of International Development, vol.14, no.4, pp 511-534.

Marr, A (2003) A Challenge to the Orthodoxy Concerning Microfinance and Poverty Reduction. Journal of Microfinance, vol.3, no.2, pp 7-42.

Marr, A, J Leon and F Ponce (2014) Financial Inclusion of the Poor in Peru. Applied Econometrics and International Development, 14 (1), pp. 101-130.

Mersland R and R O Strom (2008) Performance and trade-offs in Microfinance Organisations - Does ownership matter? Journal of International Development 20 (5): 598-612.

Rai A and T Sjöström (2004) Is Grameen Lending Efficient? Repayment Incentives and Insurance in Village Economies. Review of Economic Studies 71: 217-234.

SBS (2000), Superintendencia de Banca y Seguros del Peru. Annual Report of the Peruvian Banking Superintendency. Lima, Peru. 